\title{
Diálogo sobre las libertades y el estado Subsidiario
}

\section{Dialogue on freedoms and the subsidiary State}

\section{Hugo Ramiro Gómez Apac}

Abogado por la Universidad Nacional Mayor de San Marcos

Magíster en Derecho de la Empresa por la Universidad Peruana de

Ciencias Aplicadas

Ciudad: Lima

País: Perú

Artículo original (análisis)

RFJ, No. 7, 2020, pp. 131-156, ISSN 2588-0837

RESUMEN: El artículo, utilizando un diálogo ficticio entre un padre y su hijo, en el que el primero responde las inquietudes del segundo, explica las diferentes posiciones ideológicas que existen teniendo en consideración la intensidad en la aceptación o rechazo de las libertades individuales, sean estas económicas, políticas o civiles, utilizando para dicho propósito un plano cartesiano en el que cada cuadrante refleja una posición ideológica diferente. Luego de ello, y en tanto el vástago tiene los conceptos más claros gracias a las explicaciones de su progenitor, y siguiendo el mismo método de preguntas y respuestas, el artículo explica la diferencia que existe entre estado del bienestar y estado subsidiario, modalidades ambas de lo que se conoce como economía social de mercado.

PALABRAS CLAVE: Liberalismo, mercantilismo, economía social de mercado, estado del bienestar, estado subsidiario.

ABSTRACT: The paper, using a fictitious dialogue between a father and his son, in which the former answers the questions of the latter, explains the different ideological positions that exist based on the intensity in the acceptance or rejection of individual freedoms, such being economical, political or civil freedoms, using for this purpose a Cartesian plane in which each quadrant reflects a different ideological position. While the son has the most 
explicit concepts, thanks to his father's explanations and following the same method of questions and answers, the paper explains the difference between a welfare state and a subsidiary state, both modalities of what is known as the social market economy.

KEYWORDS: Liberalism, mercantilism, the social market economy, welfare state, subsidiary state.

\section{INTRODUCCIÓN ${ }^{1,2}$}

Desde hace tiempo teníamos la inquietud de escribir un texto que explicara las diferentes posiciones ideológicas en torno a la mayor o menor aceptación de las libertades individuales, sean estas económicas, políticas o civiles. Libertades económicas como el derecho de propiedad, la libertad de contratación, la libre iniciativa privada, la libre competencia y la libertad de empresa; libertades políticas como el voto voluntario, el derecho al sufragio de los militares, elegir o ser elegido sin importar el lugar de tu domicilio (el domiciliado en una ciudad podría postular para alcalde en otra ciudad) o nacionalidad (la posibilidad de que extranjeros sean alcaldes); libertades civiles como el matrimonio igualitario, la libre comercialización y adquisición de drogas blandas, el aborto legal, la libertad de elegir morir (eutanasia), la laicidad del estado, etc.

Frente a la división tradicional entre izquierda y derecha que resulta insuficiente para identificar el abanico de posiciones divergentes y convergentes, consideramos pertinente un esquema en el que la concepción derecha e izquierda se limite a la mayor o menor adhesión a las libertades económicas, y que la perspectiva arriba y abajo se centre en el mayor o menor consentimiento de las libertades políticas y civiles, dando como resultado un plano cartesiano en el que cada cuadrante visualiza con mayor claridad las diferentes posturas ideológicas que pueden adoptar las personas.

1 Las opiniones vertidas en el presente documento son de carácter estrictamente personal y académico, y de ninguna manera comprometen al organismo internacional en el cual el autor labora en la actualidad.

2 Resulta pertinente advertir que la noción de estado subsidiario esbozada en el presente trabajo tiene como referencia el régimen económico previsto en la Constitución Política del Perú de 1993. 
Así, mientras algunos son abanderados de todas las libertades, otros son paladines de algunas pero objetores de las restantes. Unos tienen preferencia por todas las libertades económicas pero recelo de algunas civiles. Los hay quienes son escépticos de las libertades económicas, indiferentes frente a las políticas y promotores de las civiles. Y claro que también hay espacio para aquellos que, sobre la base de querer - con fe ciega en algunos casos- un estado que se ocupe de todo, desdeñan todo tipo de libertad.

Qué duda cabe que ciertas libertades son más polémicas que otras. La libre comercialización de las drogas blandas, el matrimonio igualitario y el aborto legal generan una tirante polarización en la sociedad. Y son tan controversiales que crispan, irritan, enojan, al punto que los políticos huyen lo más que puedan de la confrontación de estos temas. No es propósito de este documento tomar partido por una o más de tales libertades, sino simplemente bosquejar un modelo que permita individualizar o ubicar las diferentes posiciones ideológicas en un plano cartesiano en función de las libertades que son apoyadas.

En el ínterin se menciona la diferencia entre liberalismo y mercantilismo, dos conceptos diferentes que suelen ser tomados como si fueran lo mismo, por error o adrede, especialmente por personas que comulgan o tienen afinidad por el comunismo o el socialismo. Finalmente, se aprovecha las nociones vertidas para abordar un asunto más complejo que es la diferenciación entre estado del bienestar y estado subsidiario. Si bien ambos modelos son expresiones de lo que se conoce como economía social de mercado, el lector podrá apreciar cierta preferencia por el segundo, en la medida que este modelo resguarda de mejor manera las libertades económicas sin menoscabar el rol solidario y de justicia social que le compete al estado. En un estado subsidiario el estado cumple un rol regulador para corregir las fallas del mercado (externalidades, bienes públicos, poder de mercado, entre otros) y tiene el deber de asegurar la provisión y cobertura de servicios esenciales (educación, salud, justicia), servicios públicos (energía, saneamiento, telecomunicaciones) e infraestructura pública (carreteras, puertos, aeropuertos, vías férreas) a toda la población, así como servicios de asistencia social a los más necesitados. 
El propio Adam Smith (1996, p. 660), padre del pensamiento liberal, reconoció que es deber del estado no solo asegurar el orden interno, la defensa externa y la administración de justicia, sino también la provisión de bienes públicos, tal como se aprecia de la siguiente cita:

Según el sistema de la libertad natural, el soberano sólo tiene tres deberes que cumplir, tres deberes de sobresaliente importancia pero que están al alcance y comprensión de una inteligencia corriente. Primero, el deber de proteger a la sociedad de la violencia e invasión de otras sociedades independientes. Segundo, el deber de proteger, en cuanto sea posible, a cada miembro de la sociedad frente a la injusticia y opresión de cualquier otro miembro de esta, o el deber de establecer un exacta administración de la justicia. Y tercero, el deber de edificar y mantener ciertas obras públicas y ciertas instituciones públicas que jamás será del interés de ningún individuo o pequeño número de individuos el edificar y mantener, puesto que el beneficio nunca podría reponer el coste que representarían para una persona o un reducido número de personas, aunque frecuentemente lo reponen con creces para una gran sociedad.

Friedrich August von Hayek (2008, pp. 70 y 71), otro de los exponentes del liberalismo, da los siguientes argumentos a favor de la regulación estatal y de la prestación de servicios sociales:

Es importante no confundir la oposición contra la planificación de esta clase con una dogmática actitud de laissez-faire. La argumentación liberal defiende el mejor uso posible de las fuerzas de la competencia como medio para coordinar los esfuerzos humanos, pero no es una argumentación en favor de dejar las cosas tal como están. Se basa en la convicción de que allí donde pueda crearse una competencia efectiva, ésta es la mejor guía para conducir los esfuerzos individuales. No niega, antes bien, afirma que, si la competencia ha de actuar con ventaja, requiere una estructura legal cuidadosamente pensada, y que ni las 
reglas jurídicas del pasado ni las actuales están libres de graves defectos. Tampoco niega que donde es imposible crear las condiciones necesarias para hacer eficaz la competencia tenemos que acudir a otros métodos en la guía de la actividad económica. El liberalismo económico se opone, pues, a que la competencia sea suplantada por métodos inferiores para coordinar los esfuerzos individuales. Y considera superior la competencia, no sólo porque en la mayor parte de las circunstancias es el método más eficiente conocido, sino, más aún, porque es el único método que permite a nuestras actividades ajustarse a las de cada uno de los demás sin intervención coercitiva o arbitraria de la autoridad. En realidad, uno de los principales argumentos en favor de la competencia estriba en que ésta evita la necesidad de un «control social explícito» y da a los individuos una oportunidad para decidir si las perspectivas de una ocupación particular son suficientes para compensar las desventajas y los riesgos que lleva consigo.

(...) Prohibir el uso de ciertas sustancias venenosas o exigir especiales precauciones para su uso, limitar las horas de trabajo o imponer ciertas disposiciones sanitarias es plenamente compatible con el mantenimiento de la competencia. La única cuestión está en saber si en cada ocasión particular las ventajas logradas son mayores que los costes sociales que imponen. Tampoco son incompatibles el mantenimiento de la competencia y un extenso sistema de servicios sociales, en tanto que la organización de estos servicios no se dirija a hacer inefectiva en campos extensos la competencia.

En un estado subsidiario el mercado le pertenece a los privados, y el estado asume en resguardo del mercado dos encargos: el de autoridad y el de empresario. Como autoridad despliega su regulación para corregir las fallas del mercado. Como empresario interviene en ausencia o defecto de la iniciativa privada. En este modelo la libre competencia reina en los mercados, y son los 
consumidores, los jueces del proceso competitivo, los que deciden quién gana y quién pierde. La teoría de la soberanía del consumidor se sustenta en la idea de que los empresarios compiten entre sí para satisfacer las preferencias del soberano consumidor, y gracias a la competencia, a la rivalidad de las empresas en el mercado, los consumidores obtienen productos y servicios a menores precios, de mejor calidad, en mayor variedad y de más fácil acceso. La noción de soberanía del consumidor es explicada magistralmente por Luwing von Mises (2018, pp. 328 y 329) en los siguientes términos:

En la sociedad de mercado corresponde a los empresarios la dirección de los asuntos económicos. Ordenan la producción. Son los pilotos que dirigen el navío. A primera vista, podría parecernos que son ellos los supremos árbitros. Pero no es así. Están sometidos incondicionalmente a las órdenes del capitán, el consumidor. Ni los empresarios ni los terratenientes ni los capitalistas deciden qué bienes deban ser producidos. Eso corresponde exclusivamente a los consumidores. Cuando el hombre de negocios no sigue, dócil y sumiso, las directrices que, mediante los precios del mercado, el público le marca, sufre pérdidas patrimoniales; se arruina y acaba siendo relevado de aquella eminente posición que ocupaba al timón de la nave. Otras personas, más respetuosas con los mandatos de los consumidores, serán puestas en su lugar.

Los consumidores acuden a donde le ofrecen a mejor precio las cosas que más desean; comprando y absteniéndose de hacerlo, determina quiénes han de poseer y administrar las plantas fabriles y las explotaciones agrícolas. Enriquecen a los pobres y empobrecen a los ricos. Precisan con el máximo rigor lo que deba producirse, así como la cantidad y calidad de las mercancías. Son como jerarcas egoístas e implacables, caprichosos y volubles, difíciles de contentar. Sólo su personal preocupación les preocupa. No se interesan ni por méritos pasados ni por derechos un día adquiridos. Abandonan a sus tradicionales proveedores en 
cuanto alguien les ofrece cosas mejores o más baratas. En su condición de compradores y consumidores, son duros de corazón, desconsiderados por lo que a los demás se refiere.

(...) Sólo ateniéndose rigurosamente a los deseos de los consumidores pueden los capitalistas, los empresarios y los terratenientes conservar e incrementar su riqueza. No pueden incurrir en gasto alguno que los consumidores no estén dispuestos a reembolsarles pagando un precio mayor por la mercancía de que se trate. Al administrar sus negocios han de insensibilizarse y endurecerse, precisamente por cuanto los consumidores, sus superiores, son a su vez insensibles y duros.

En el modelo regido por el principio de subsidiariedad, el estado tiene un deber especial de garantizar una educación pública de calidad al alcance de todos. Una buena educación genera una fuerza laboral más capacitada, lo que a su vez genera innovación e incrementa la productividad, impulsores del crecimiento económico. Adam Smith (1996, p. 719) reconoció la importancia de la educación pública al afirmar que "La educación del pueblo llano requiere quizás más la atención del estado en una sociedad civilizada y comercial que la de las personas de rango y fortuna." Mario Vargas Llosa (2018, p.27), Premio Nobel de Literatura 2010 y un vocero autorizado del ideario liberal, nos dice lo siguiente con relación a la educación pública:

Por esa razón es tan importante, para el liberalismo, ofrecer a todos los jóvenes un sistema educativo de alto nivel que asegure en cada generación un punto de partida común, que permita luego las legítimas diferencias de ingreso de acuerdo al talento, al esfuerzo y al servicio que cada ciudadano presta a la comunidad. En el mundo de la educación -escolar, técnica y universitaria- es donde más injusto es el privilegio, es decir, favorecer con una formación de alto nivel a ciertos jóvenes condenando a los otros a una educación somera o ineficiente que los conduce a un futuro limitado, al fracaso o a la mera supervivencia. Esto 
no es una utopía, sino algo que, por ejemplo, Francia consiguió en el pasado con una educación pública y gratuita que solía ser de más alto nivel que la privada y estaba al alcance de toda la sociedad...

Un estado subsidiario tampoco descuida la salud de la población. La pandemia del Covid-19 (Coronavirus) nos recuerda la importancia de los sistemas públicos de seguridad social y los servicios asistenciales (v.g. las beneficencias públicas). Sobre la intervención del estado en caso de calamidad pública, vale la pena leer el siguiente párrafo de Friedrich A. Hayek (2008, pp. 124 y 125):

No existe tampoco razón alguna para que el Estado no asista a los individuos cuando tratan de precaverse de aquellos azares comunes de la vida contra los cuales, por su incertidumbre, pocas personas están en condiciones de hacerlo por sí mismas. Cuando, como en el caso de la enfermedad y el accidente, ni el deseo de evitar estas calamidades, ni los esfuerzos para vencer sus consecuencias son, por regla general, debilitados por la provisión de una asistencia; cuando, en resumen, se trata de riesgos genuinamente asegurables, los argumentos para que el Estado ayude a organizar un amplio sistema de seguros sociales son muy fuertes. En estos programas hay muchos puntos de detalle sobre los que estarán en desacuerdo quienes desean preservar el sistema de la competencia y quienes desean sustituirlo por otro diferente; y es posible introducir bajo el nombre de seguros sociales medidas que tiendan a hacer más o menos ineficaz la competencia. Pero no hay incompatibilidad de principio entre una mayor seguridad, proporcionada de esta manera por el Estado, y el mantenimiento de la libertad individual. A la misma categoría pertenece también el incremento de seguridad a través de la asistencia concedida por el Estado a las víctimas de calamidades como los terremotos y las inundaciones. Siempre que una acción común pueda mitigar desastres contra los cuales el individuo ni puede intentar protegerse a sí mismo ni prepararse para sus consecuencias, esta acción común debe, sin duda, emprenderse. 
El plano cartesiano de las posiciones ideológicas, la diferencia entre liberalismo y mercantilismo y la disimilitud entre estado del bienestar y estado subsidiario son explicados simulando el diálogo entre un padre y su hijo. La curiosidad de este sirve de pretexto para que el padre exponga y desarrolle paso a paso los conceptos antes mencionados, de modo que el lector, testigo del diálogo, se zambulle en la mente de los interlocutores y va navegando con ellos en una tertulia que busca resaltar la importancia de buscar consensos a partir de la defensa de las libertades y de la necesidad de que la intervención del estado en la economía tenga límites bien definidos.

\section{EL PLANO CARTESIANO Y LA BÚSQUEDA DE CONSENSOS A PARTIR DE LA DEFENSA DE LAS LIBERTADES}

Padre e hijo tenían pendiente esta conversación. Encerrados por la cuarentena encontraron el momento propicio. El hijo inició el diálogo.

- Me parece difícil que alguien de izquierda se pueda poner de acuerdo con alguien de derecha.

-Eso depende de qué tan a la izquierda o a la derecha estén. No hay una única posición de izquierda o de derecha. Hay diversas posiciones. Imagina un punto negro. Ahora traza mentalmente una línea horizontal que atraviesa ese punto. En esa línea horizontal, el punto negro es el centro. A su derecha imagina diversos puntos de color azul, lo mismo que a su izquierda de color rojo. Si has hecho lo que estoy pensando, en la línea horizontal hay puntos azules a la derecha que están cerca al centro y otros que se alejan hacia la derecha. De igual manera, hay puntos rojos a la izquierda que están cerca del centro y otros se alejan hacia la izquierda.

— ¡Ah! ¡Ya entiendo! Es difícil que se pongan de acuerdo los que están en la extrema izquierda con los que están en la extrema derecha, pero los de la izquierda que están cerca del centro se pueden poner de acuerdo con los de la derecha que también están cerca del centro. 
_ ¡Exacto! Un comunista que cree que el estado debe ser el propietario de todos los factores de producción (tierra, capital, máquinas y trabajo) nunca se va a poner de acuerdo con un libertario que cree que el estado solo debe asegurar el orden interno (con leyes, jueces y policías) y la defensa externa (con las fuerzas armadas) y mantener las relaciones exteriores (con embajadores y cónsules).

- Porque ese comunista es de extrema izquierda y ese libertario de extrema derecha.

-Así es, pero tengo que hacer una aclaración. Para simplificar las cosas he dividido la izquierda de la derecha en función del grado de intervención del estado en la economía. Así, la izquierda refleja a quienes creen que el estado debe intervenir bastante, al punto que la extrema izquierda la identifico con el comunismo en el que no hay mercado sino solo estado. Por su parte, la derecha la identifico con quienes se oponen a una excesiva intervención del estado, colocando en la derecha extrema a los libertarios que creen que el estado no debe intervenir para nada en el mercado. Hago esta aclaración porque el término "extrema derecha" también alude a un sector que si bien cree "algo" en el mercado, es entre comillas "moralmente" conservador.

-Explícame sobre esa "extrema derecha”.

-Esa "extrema derecha" no es liberal. Que crea "algo" en el mercado significa que solo cree en el mercado cuando le conviene; es decir, es un mercantilista. Un liberal no piensa así. Un liberal cree en el mercado independientemente de si gana o pierde en el mercado. Un liberal cree en el mercado en el sentido de que la libre competencia decide qué empresario gana y qué empresario pierde. Un mercantilista cree en la propiedad privada porque tiene propiedades y cree en la competencia en tanto ésta le permita ganar dinero. Pero si para ganar dinero, o para evitar perderlo, tiene que olvidarse de la competencia, lo hará. Es mercantilista el que le pide al estado privilegios para ganar dinero, como por ejemplo tener el monopolio de la fabricación o venta de un producto determinado. Es mercantilista el que le pide al estado destruir a sus competidores a través del incremento de los aranceles o la imposición de limita- 
ciones o barreras para entrar al mercado. El liberal no le tiene miedo a la competencia, el mercantilista sí. El mercantilismo genera corrupción pues a través de coimas busca la obtención de ventajas o privilegios que solo el estado puede dar. El mercantilismo es ineficiente porque es fuente de barreras burocráticas que entorpecen el acceso y permanencia de los agentes económicos en el mercado. Por otro lado, un liberal cree en la libertad, en todo tipo de libertad. Cree tanto en las libertades económicas (derecho de propiedad, libertad de contratación, libre iniciativa privada, libre competencia y libertad de empresa) como en las libertades políticas y civiles. Libertades políticas como el voto voluntario o el derecho al sufragio de los militares, y libertades civiles como el matrimonio entre homosexuales, el estado laico o la libre comercialización de las drogas, al menos las llamadas drogas blandas. Respecto de tales libertades, esa "extrema derecha" es conservadora. Para empezar, es religiosa. Considera que el estado, en lugar de ser laico, debe promover las ideas y principios de una determinada religión, quiere un estado confesional. Segundo, no le gusta ciertas libertades civiles. Se opone al matrimonio igualitario, lo mismo que a la legalización de las drogas. Ahora bien, dije entre comillas "moralmente" porque esa "extrema derecha" combate lo que ella considera que es inmoral. El problema es que lo que es inmoral para unos puede no serlo para otros. Para unos puede ser inmoral las relaciones sexuales prematrimoniales, para otros no. Para unos puede ser inmoral las relaciones sexuales entre personas del mismo sexo, para otros no. Para unos puede ser inmoral que un hombre de sesenta años se case con una mujer de veinte, para otros no. La moral depende del grupo religioso al que perteneces, de tu entorno social o, en el extremo, depende de cada uno.

-Entonces esa "extrema derecha" es mercantilista y conservadora. Es mercantilista porque cuando la competencia no le conviene, le pide al estado privilegios. Y es conservadora porque le incomodan ciertas libertades civiles.

-Así es.

-Entonces tendríamos que definir mejor la diferencia entre izquierda y derecha. 
- Hay una forma. Visualiza nuevamente la línea horizontal. Ahora córtala por el centro mediante una línea vertical. Lo que verás (en tu mente) es un plano cartesiano (coordenadas cartesianas). Cuatro cuadrantes y el centro (recuerda el punto negro) que es el origen de cada cuadrante. La línea horizontal es el eje de las abscisas y donde están los puntos $x$, mientras que la línea vertical es el eje de las ordenadas y donde están los puntos $y$. Que la línea o eje horizontal (de los puntos $x$ ) refleje, como te lo expliqué hace un momento, el grado de intervención del estado en la economía. A la derecha del centro, los puntos $x$ positivos (los azules) que expresan la menor intensidad de la participación del estado como regulador y empresario o, dicho en otras palabras, la intensidad de la libertad económica. A la izquierda, los puntos $x$ negativos (los rojos) que expresan la mayor intensidad de la participación regulatoria y empresarial del estado, que también podemos traducirla en una menor libertad económica. Vista así las cosas, cuanto más a la derecha en la línea horizontal (los puntos $x$ positivos) más libertad económica; y cuanto más a la izquierda (los puntos $x$ negativos) menos libertad económica. La línea o eje vertical, por su parte, que exprese el nivel de aceptación por las libertades políticas y civiles. Así, la parte superior de la línea vertical (los puntos y positivos, que también sean azules), o sea del centro para arriba, que refleje la aceptación por las libertades políticas y civiles, en el sentido de que cuanto más hacia arriba mayor la aceptación por tales libertades. Por el contrario, que la parte inferior de la línea vertical (los puntos $y$ negativos, de color rojo), que va del centro para abajo, evidencie el nivel de oposición hacia las libertades políticas y civiles, de modo que cuanto más hacia abajo mayor la oposición hacia tales libertades. En este plano cartesiano hay cuatro cuadrantes: el superior derecho, el superior izquierdo, el inferior derecho y el inferior izquierdo.

- ¡Ya entendí! En el cuadrante superior derecho están aquellos a favor de mayor libertad económica (menos regulación y actividad empresarial del estado) y con mayor aceptación a las libertades políticas y civiles. En el cuadrante superior izquierdo están los que si bien creen en una mayor regulación y actividad empresarial estatal (menos libertad económica), están a favor de las libertades políticas y civiles. En el cuadrante inferior derecho están a favor 
de mayor libertad económica, pero en contra de las libertades políticas y civiles. Y en el cuadrante inferior izquierdo lo que están en contra de todas las libertades. «¿Quién en su sano juicio puede estar en contra de todas las libertades?» «¿Quién quiere ser esclavo del estado?»

-Bien, pero recuerda que es un tema de intensidades. Cuanto más vas hacia un lado, derecha, izquierda, arriba o abajo, se incrementa o disminuye, según cada caso, la defensa de una determinada libertad. Imagina un libertario que cree de manera absoluta en todas las libertades. Él estará en el cuadrante superior derecho, alejado del centro y en un punto equidistante entre el eje horizontal y el eje vertical. Ahora imagina alguien que cree con vehemencia en la libertad económica, pero solo acepta una que otra libertad política. Su ubicación será diferente. Estará en el cuadrante superior derecho, alejado del centro, pero cercano a la línea horizontal. En cambio, si fuera un defensor a ultranza de las libertades políticas y civiles, pero un promotor tímido de la libertad económica, estará en el cuadrante superior derecho, alejado del centro pero cercano al eje vertical.

-Entiendo. Déjame dar otro ejemplo. Si alguien cree a ultranza en las libertades políticas y civiles, pero cree que el estado debe tener un rol regulador y empresarial un poco mayor al vigente estará en el cuadrante superior izquierdo, alejado del centro pero cercano a la línea vertical.

-Sí.

-Y un comunista contrario a todas las libertades estará en el cuadrante inferior izquierdo, muy alejado del centro y en un lugar intermedio entre las líneas vertical y horizontal.

— ¡Muy bien! Como todos piensan diferente, las intensidades varían. La ideología que profesan ubica a las personas en puntos diferentes dentro de los cuadrantes. Es normal que alguien esté a favor de una libertad pero en contra de otra. Mucha gente joven de izquierda, que se considera progresista, está a favor del matri- 
monio igualitario (libertad civil), pero exige una mayor regulación estatal (menos libertad económica) en los temas ambientales. ¿Dónde los ubicas?

-En el cuadrante superior izquierdo.

-Correcto.

-El plano cartesiano, donde hay izquierda derecha, arriba y abajo, explica mejor la diferenciación política de la simple dicotomía izquierda y derecha.

-En principio, sí, pero tengo que precisarte algo. Para facilitar la explicación metí en un mismo saco a las libertades políticas con las civiles. Sin embargo, para muchas personas son cosas completamente diferentes, de modo que pueden estar a favor de unas pero en contra de otras. Por ejemplo, muchas personas están a favor del matrimonio entre homosexuales (libertad civil) pero en contra del voto voluntario (libertad política).

- ¿Qué me vas a proponer, un plano cartesiano tridimensional que diferencie los tres tipos de libertades?

-No. Sería muy complicado. En esta conversación no puedo ir más allá del plano cartesiano. Posiblemente si supiera programar podría diseñar un esquema como el que mencionas. Por ahora confórmate con el plano cartesiano bidimensional.

-De acuerdo, ja, ja, ja...

-Lo que importa es que podemos diferenciar la ideología de las personas, en lugar de simplemente izquierda y derecha, por las libertades que defienden, y dependiendo de esto se pueden lograr más o menores consensos. Por ejemplo, asumamos que Fulano está a favor de mayores libertades políticas (voto voluntario, ser elegido independientemente de tu lugar de domicilio, etc.), cauto con respecto a las libertades civiles (a favor del matrimonio igualitario, pero en contra del aborto y de la legalización de la 
comercialización de las drogas) y moderado en cuanto a la libertad económica (considera que el estado sí debe regular cuando hay fallas del mercado). Fulano bien puede conversar y ponerse de acuerdo con Mengano, quien está a favor de ciertas libertades políticas (voto voluntario y ser elegido independientemente de tu lugar de domicilio), más agresivo con las libertades civiles (a favor del matrimonio igualitario, a favor de la legalización únicamente de la comercialización de la marihuana y en contra del aborto) e igual de moderado que el anterior con relación a la libertad económica. Fulano y Mengano no piensan exactamente igual, pero tienen ciertas afinidades en cuanto a las libertades que defienden, lo que permite que pueden ponerse de acuerdo, si es que son capaces de ceder un poco en sus posiciones.

- Lo que planteas es que la búsqueda de acuerdos se haga a partir de las libertades que defienden las personas.

_iExactamente! Ahora piensa nuevamente en el plano cartesiano (bidimensional), y olvida por un momento la diferencia entre las libertades políticas y civiles. Dibuja un círculo cuyo centro es el centro del plano cartesiano. Piensa en el radio del círculo. Cuanto más grande el radio, el círculo ocupará una mayor extensión dentro del plano cartesiano. ¿Lo tienes?

-Sí, lo tengo. Si hubiera sabido que íbamos a tener esta conversación, habría traído una pizarra.

-La mente es más amplia que una pizarra. El círculo puedes dividirlo, al igual que el plano cartesiano, en cuatro cuadrantes, utilizando los ejes horizontal y vertical.

-En la pizarra que hay en mi mente visualizo un círculo cuyo centro es el centro del plano cartesiano. No me mires así -dijo mientras observaba la cara burlona de su interlocutor-. Estoy viendo - continuó mientras sonreía y cerraba los ojos- los dos ejes del plano cartesiano que se cortan en el centro, que a su vez es el centro del círculo. La circunferencia ocupa aproximadamente la mitad del plano cartesiano. El círculo está dividido, como una pizza, en cuatro cuadrantes: superior derecha, superior izquierda, inferior 
derecha e inferior izquierda. Como es obvio, cada cuadrante es un cuarto de círculo.

—No quiero que imagines un círculo grande, sino un pequeño.

- ¿Por qué uno pequeño?

-Porque cuanto más pequeño es el círculo, más cercana son las posiciones de las personas ubicadas en los cuatro cuadrantes. Si el círculo es pequeño, las posiciones son, por decirlo de alguna manera, moderadas. Defienden las libertades, pero no a ultranza. Defienden el rol regulador y empresarial del estado, pero con reservas. En este círculo pequeño, está el conjunto de personas que, conscientes o no, conforman un espacio cercano el centro político.

— ¡El centro político!

-El centro político. No es el cielo ni el infierno, es el limbo. El centro político es el lugar favorito de los políticos. Piensan que van a ganar una elección si son identificados como de centro. Asumen que los de la derecha no van a votar por los de la izquierda ni éstos por los anteriores, pero que ambos pueden votar por el centro. En política es el mal menor. Para la derecha, la izquierda es el mal mayor y el centro el mal menor. Para la izquierda, el mal mayor la derecha, el mal menor el centro. Además, desde el centro puedes eludir los temas más peliagudos. ¿Estás de acuerdo con el aborto? Defiendo tanto la vida del concebido como la libertad de la madre. ¿Estás de acuerdo con el matrimonio homosexual? Defiendo los valores cristianos y también los derechos de las minorías. ¿Estás de acuerdo con el voto voluntario? Votar es un deber cívico pero también una libertad. ¿Estás de acuerdo con un sistema bicameral (cámara de diputados más cámara de senadores)? Dos cámaras aseguran una mayor reflexión en la aprobación de leyes pero no podemos desperdiciar los recursos en más congresistas.

- ¡No tiene sentido! Dice una cosa y luego la contradice. El centro parece que no es lo uno ni lo otro, sino todo lo contrario. 
—Ja, ja, ja...-No pudo contener la risa- ¡Tienes razón! El centro es un engaña muchachos. Quiere quedar bien con todos, por lo que le da la razón a todos. Las propuestas de centro son ininteligibles. Ofrece construir carreteras y bajar los impuestos, y claro, no te explica cómo va a construir carreteras con menos recursos públicos. El centro le ofrece a los jóvenes más puestos de trabajo y a los sindicatos estabilidad laboral, lo que es un contrasentido. Pero el centro es así. No sólo eso. Es anodino, incapaz de tomar acción, incapaz de revolucionar. El centro es el lugar ideal para dar trabajo a burócratas que tienen miedo de todo. Al centro le gusta las mesas de trabajo, el debate, la consulta, el pedido de informes, el planeamiento, y luego más debate, más consulta, más informes y la reformulación del planeamiento, y para tener certeza absoluta de que nadie pierde y todos ganan, un poco más de debate, una última consulta, los informes finales y el planeamiento acabado, y justo cuando hay que ejecutar, cuando hay que tomar acción, se acabó el tiempo, terminó el periodo, viene un nuevo alcalde, un nuevo director, un nuevo ministro, y a empezar nuevamente todo, mesa de trabajo, consulta...

—¿Dios mío! ¿Qué propones entonces?

-El cuadrante que defiende libertades. El pequeño cuadrante superior derecho. El cuadrante es pequeño porque el círculo es pequeño. Si el cuadrante fuera grande, las posiciones a ultranza espantarían a los votantes. El político tiene que ser pragmático. El cuadrante superior derecho es el elegido, pero tiene que ser pequeño. Esto significa defender las libertades, pero sin posiciones extremas. Creo que allí radica la oportunidad del consenso. Además, ese cuadrante puede albergar sin problema alguno la noción de "economía social de mercado”, que es el sistema económico reconocido en la constitución anterior, en la vigente y si en el futuro hay una nueva constitución, estoy seguro que va a decir lo mismo.

- Me estás diciendo que podemos hablar de economía social de mercado en el pequeño cuadrante superior derecho.

-Sí, pero con una precisión. 
— ¡Ya lo sabía, siempre hay una precisión!

- La economía social de mercado la puedes subdividir en dos versiones: el estado del bienestar y el estado subsidiario.

\section{EL ESTADO SUBSIDIARIO}

El hijo tenía los conceptos más claros, especialmente donde ubicar el pensamiento de su padre: el cuadrante superior derecho. Ahora venía un asunto más complicado, diferenciar al estado subsidiario del estado del bienestar. El padre inició la conversación.

- La economía social de mercado la puedes subdividir en dos versiones: el estado del bienestar y el estado subsidiario.

—¿Cuál es la diferencia?

-En el de bienestar el estado está autorizado a crear empresas públicas por razones de "interés social", y también por este interés puede expropiar, controlar precios y extender el manto de su regulación. No sólo eso. Dicho interés puede resultar suficiente para planificar (que es más que regular) la actividad económica de los privados.

— ¿Y qué exactamente es ese interés social?

-Buena pregunta, difícil respuesta. Teóricamente es aquello que beneficia a todos. En la práctica es lo que el político "cree" que beneficia a todos. En realidad es lo que al político le conviene, por ejemplo porque le podría conceder más votos. Si quiere congraciarse con sus votantes podría proponer que la población merece transportarse de manera más rápida, cómoda y barata y que por tanto deben crearse empresas estatales para prestar los servicios de transporte marítimo, fluvial, aéreo y terrestre por carretera y vías férreas. Y claro, es de interés social que el transporte sea más rápido, cómodo y barato. También podría sugerir que la población tiene derecho a comer pan, leche, arroz y azúcar a un menor precio y en consecuencia que el gobierno debe establecer un control de precios a los productos de primera necesidad. Sólo bastaría decir que es de “interés social”. Es la palabra mágica. 
—¿Cuál es el límite?

-En el estado del bienestar el límite no es claro. El estado podría ser dueño de cines, restaurantes, peluquerías, equipos de fútbol.

— ¿Y en el estado subsidiario?

-Empecemos por entender el concepto de "subsidiario". Algo es subsidiario cuando respalda otra cosa que es lo principal. Ese algo que es subsidiario tiene por objeto apoyar lo principal. Lo principal es que la economía está en manos de los ciudadanos, el mercado le pertenece a los privados; sin embargo, no puedes dejar al mercado en manos únicamente de los particulares, pues algunos empresarios podrían abusar de (o engañar a) otros empresarios o de los consumidores, o la negligencia de unos podría dañar la vida, salud o los bienes de terceros, por lo que es necesario el respaldo del estado, su intervención como autoridad para evitar abusos, engaños, accidentes y daños en general. Esa intervención del estado como autoridad se llama regulación. El estado regula las actividades económica para evitar daños y otras situaciones perjudiciales. Pero además de actuar como autoridad, el estado suele ofrecer (ofertar) al mercado bienes o servicios, esto es, actúa como empresario, caso en el cual lo subsidiario significa que el estado actúa en respaldo de la iniciativa privada o en defecto de esta; es decir, si el sector privado no puede realizar algo, o lo hace defectuosa o insuficientemente, entonces ese algo lo hace el estado como respaldo y para beneficio de la población desatendida por el sector privado.

-Con lo que me explicas no logro entender la diferencia entre estado del bienestar y subsidiario. Me queda claro que el de bienestar puede actuar casi sin límites, o que su límite es esa noción gaseosa de "interés social", por lo que al ser tan etéreo no queda claro cuáles son sus límites.

-En el estado subsidiario el contorno de los límites es más claro. El estado puede expropiar pero solo por razones de seguridad nacional o necesidad pública, como para construir una carretera o un puente. Puede realizar actividad empresarial pero solo si el mercado no es capaz de proveer determinado bien o servicio, o pudiendo 
hacerlo hay segmentos de la población que no pueden acceder a la oferta privada de dicho bien o servicio. Bajo el rol subsidiario del estado, este tiene el deber de proveer servicios de educación (escolar y universitaria) y salud de calidad a las personas que no pueden pagar o tienen dificultades para pagar las pensiones de los colegios y universidades privadas y los precios de las clínicas particulares.

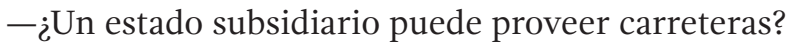

-Por supuesto, y también puertos, aeropuertos, vía férreas y redes de energía (electricidad, gas natural), de servicios de saneamiento (agua potable y alcantarillado) y de telecomunicaciones (telefonía, internet). El esquema es sencillo. Si el mercado pertinente (o relevante) es rentable, es decir, hay más de un empresario dispuesto a proveer el servicio o infraestructura, el gobierno, previo concurso público abierto y transparente, adjudicará la concesión al empresario que ofrezca la mejor combinación en cuanto a precio, cobertura y calidad. Dado que la concesión es temporal, cuando esta termine se hace un nuevo concurso público. Así el estado puede asegurar la provisión de servicios e infraestructura de carácter público sin tener que gastar recursos públicos, lo que permite ahorrar para brindar los otros servicios que la sociedad requiere, como educación y salud que hace un momento mencioné, así como justicia y los de carácter asistencial, como las beneficencias públicas para dar cobijo y alimentación a los que nada tienen.

${ }_{-}$Y si el mercado pertinente no es rentable? Pensemos en una carretera que une a dos pueblos pequeños y como tiene poco tráfico vehicular ningún privado estaría dispuesto a asumir una concesión en ese lugar.

- Si el mercado relevante no es rentable el estado puede utilizar otras formas de asociación público privada (APP). Puede otorgar la concesión para la construcción y mantenimiento de una carretera mediante un concurso público por el menor subsidio. Asumamos que el costo de construir (o ampliar) y mantener una carretera por 10 años es, en principio, diez millones de unidades, pero hay escaso tráfico vehicular y los pocos que circulan son personas de mínimos recursos. En un escenario así no funcionaría una 
concesión autofinanciada, pero sí una financiada por el estado pero operada por un privado. Bajo un concurso por el menor subsidio, la idea sería adjudicar la concesión al empresario que, al menor costo posible, puede construir y mantener la susodicha carretera por 10 años. Imaginemos que un postor ofrece nueve millones y otro ocho. Se le adjudicaría la concesión a este último. El estado estaría asegurando la provisión de la infraestructura (la carretera), pero no de manera directa sino a través de la iniciativa privada (el concesionario), y ahorrando dos millones, que los puede destinar para otras necesidades de la población. Este esquema lo puedes utilizar para proveer puertos, aeropuertos, líneas de transmisión eléctrica, el suministro de agua potable y, también, para la administración de universidades y hospitales públicos.

-En un estado subsidiario el estado no desatiende las necesidades públicas, solo que busca que dichas necesidades sean colmadas al menor costo posible a través del sector privado.

-En un estado subsidiario toda actuación, intervención o medida del estado debe tener más beneficios que costos. Asegurar la provisión del servicio público, asegurar su cobertura y calidad, pero al menor costo posible. Pongamos el caso de una universidad pública. Para empezar el estado debe garantizar que la universidad funcione, pero que funcione bien, que tenga bibliotecas, computadoras, pizarras, laboratorios, buenos profesores, etc. Dicha universidad puede ser gestionada por el propio estado o por un privado. El hecho de que la administración sea privada no significa que la universidad deje de ser pública. Es pública porque le pertenece al estado y porque su finalidad es que estudien en ella los que no tienen recursos para pagar una educación privada. Si es más eficiente la gestión (administración) pública que la privada, se optará por lo primero. Pero si el estudio arroja lo contrario, lo correcto sería un concurso público para que una persona jurídica, al menor costo posible, administre la universidad pública asegurando que el servicio sea de calidad, tal como lo merecen los ciudadanos. Empresas o asociaciones que ya administran otras universidades tendrían el perfil para postular al concurso público. Nota que el gasto a fin de cuentas viene del estado, solo que la gestión se encarga al sector privado. Si este falla, si lo hace 
mal, se revoca la concesión (o el título habilitante que se use) y regresa la administración al estado o se hace un nuevo concurso público. Pero incluso puede haber otra opción. Recuerda que el objetivo es que los ciudadanos tengan acceso a una educación pública de calidad, por lo que no necesariamente el estado tiene que implementar una universidad. Puede otorgar becas, si es que esta opción es más eficiente. Dado que ya existen universidades privadas, algunas de ellas con mucho prestigio debido a la buena calidad de su servicio, podría ser mejor que cada año el estado otorgue becas completas (alimentación, vivienda y el pago de las pensiones) a los alumnos con mejores notas provenientes de los colegios estatales. La ventaja de este sistema no solo es el ahorro en construir o mantener una universidad pública, sino que los estudiantes de menores recursos tienen la oportunidad de recibir esa educación de calidad provista por las universidades de mayor prestigio. Todos ganan. Las universidades con mayor reputación son premiadas con la asignación de becarios, que significa ingresos para ellos, y los mejores alumnos de los colegios públicos son premiados por su esfuerzo.

- Lo importante es que los ciudadanos tengan acceso a una educación pública de calidad, lo que es deber del estado, e independientemente de si la gestión del servicio lo hace el estado o el sector privado, el que lo haga mejor.

_ ¡Exactamente! De eso trata el principio de subsidiariedad, que el sector privado haga aquello que lo puede hacer de manera más óptima que el estado, porque si no lo puede hacer mejor, que el estado siga a cargo del servicio.

—En un estado subsidiario sí hay justicia social.

—iAsí es! Un estado subsidiario implica una adecuada combinación de los principios de subsidiariedad y solidaridad. Lo importante es tener claro los límites. Si el mercado y la competencia son capaces de proveer el servicio de manera eficiente (calidad y cobertura), no hace falta que el estado intervenga. Si el sector privado no tiene interés porque el mercado no es rentable, el estado debe hacerse cargo, y como vimos no necesariamente de manera directa, sino 
que puede encargarle el asunto, vía concurso público, a un privado. Ello, sin perjuicio del rol regulador del estado para evitar los abusos que los privados pueden efectuar en perjuicio de otros privados. El estado tiene la autoridad (su poder de imperio) para asegurar que en los mercados haya competencia, que se respeten los derechos de los usuarios y consumidores y, además, regular toda aquella situación con el objetivo de evitar abusos, engaños, estafas, accidentes, enfermedades y daños en general.

-Como declarar estados de emergencia para combatir una pandemia como la que nos aflige.

-En efecto, estamos en cuarentena porque el gobierno, ante una situación excepcional y de emergencia, ha recortado unas cuantas libertades para salvar la vida de toda la población. Es más beneficioso para todos permanecer dentro de nuestras casas que asumir el costo de sufrir los efectos de un contagio masivo que mate a miles o decenas de miles de personas.

${ }_{-}$En un estado subsidiario se puede limitar la libertad de empresa?

-Sí, pero no por una idea vaga de lo que significa "interés social", sino ante una situación de extrema gravedad (la muerte inminente de decenas o centenas de miles de personas) que justifique la declaración de estado de emergencia, situación en la cual el estado podría, por ejemplo, obligar a las empresas a fabricar mascarillas, respiradores artificiales, alcohol en gel, vacunas, etc., pagando el precio correspondiente.

-Un estado subsidiario respeta en mayor medida las libertades económicas que un estado del bienestar, sin que ello signifique desamparar a la población frente a amenazas graves como una pandemia. Un estado subsidiario encaja en el pequeño cuadrante superior derecho.

—Lo has entendido - le respondió sonriendo. 


\section{CONCLUSIONES}

Para fines metodológicos hemos dividido las libertades individuales en económicas, políticas y civiles. No hay consenso en la defensa de tales libertades. Hay desde quienes defienden todas ellas, los libertarios, hasta los que las niegan por completo, los comunistas totalitarios. Entre uno y otro extremo hay diferentes posiciones divergentes y convergentes que no pueden ser ubicadas de manera coherente bajo la clásica división derecha e izquierda, por lo que en su lugar se postula un plano cartesiano que acoge en sus cuadrantes, y en diferentes posiciones de cada cuadrante [más cerca o lejos del centro y de los ejes de las abscisas (donde están los puntos $x$ ) y de las ordenadas (donde están los puntos $y$ )] una multiplicidad de posibilidades sobre la base de considerar en el eje horizontal (de las abscisas) la defensa (a la derecha del centro) o rechazo (a la izquierda del centro) de las libertades económicas (el derecho de propiedad, la libertad de contratación, la libre iniciativa privada, la libre competencia y la libertad de empresa) y en el eje vertical (de las ordenadas) la aceptación (arriba del centro) o negación (abajo del centro) de las libertades políticas (por ejemplo el voto voluntario) y civiles (el matrimonio igualitario, el aborto legal, el estado laico, entre otros).

Habrá quienes defienden las libertades económicas pero solo algunas de las políticas y civiles. Otros rechazarán las libertades civiles (especialmente las más controversiales que polarizan a la sociedad) pero podrían ser conservadores con las libertades económicas (aceptar una intervención moderada del estado como regulador y empresario). Un sector podría mostrarse opuesto a las libertades económicas (exigiendo por tanto una mayor intervención del estado en la economía) pero ser paladín de las libertades civiles. Y así dependiendo de las libertades que la persona apoya o desestima será ubicada no solo en un cuadrante en particular, sino en un lugar dentro de ese cuadrante: más cercano o alejado del centro, más próximo a la línea vertical o a la horizontal. Así por ejemplo, un libertario que cree de manera absoluta en todas las libertades estará en el cuadrante superior derecho, alejado del centro y en un punto equidistante entre el eje horizontal y el vertical. En cambio, un comunista totalitario que rechaza todas 
las libertades estará en el lado opuesto, en el cuadrante inferior izquierdo, muy alejado del centro y en un lugar intermedio entre las líneas vertical y horizontal.

Un segundo tema abordado en el presente documento es la diferencia entre estado del bienestar y estado subsidiario, dos expresiones de lo que se conoce como economía social de mercado. El estado del bienestar se caracteriza por una intervención dilatada del estado como regulador (y hasta planificador) y una participación extendida como empresario. La creación de empresas estatales se sustenta en el "interés social", un concepto tan amplio, ambiguo y etéreo que origina que los límites de la actividad empresarial del estado no estén bien delimitados, pudiendo participar prácticamente en cualquier actividad, independientemente de las condiciones de competencia del mercado de que se trate. En cambio, en el estado subsidiario la regulación se implementa para corregir las fallas del mercado (externalidades, bienes públicos, poder de mercado, etc.) y siempre que sus beneficios sean mayores a sus costos. Asimismo, en este modelo la actividad empresarial del estado está sujeta al principio de subsidiariedad, según el cual el estado está autorizado a ofrecer al mercado determinados bienes o servicios siempre y cuando no haya oferta privada capaz de proveer tales bienes o servicios, o habiéndola, haya segmentos de la población que carecen de los recursos para acceder a la oferta privada. En el estado subsidiario se complementan de modo armónico los principios de libertad y solidaridad. Entendido así el estado subsidiario, este modelo respeta en mayor medida las libertades económicas sin descuidar el rol promotor y solidario del estado que, sobre la base de garantizar la justicia social, atiende las necesidades de la población con menos recursos.

A través del diálogo ficticio entre un hijo y su padre, las dudas y preguntas del primero y las respuestas del segundo, el lector se inmiscuye en la conversación familiar y descubre paso a paso la importancia de buscar consensos a partir de la defensa de las libertades y de la necesidad de que la intervención del estado en la economía tenga límites bien definidos. 


\section{REFERENCIAS BIBLIOGRÁFICAS}

Hayek, F. A. (2008). Camino de servidumbre: Textos y documentos, España - Madrid: Biblioteca de la Libertad - Unión Editorial S.A.

Smith, A. (1996). La riqueza de las naciones, España - Madrid: El Libro de Bolsillo - Alianza Editorial, S.A.

Vargas Llosa, M. (2018). La llamada de la tribu, primera edición, Perú - Lima: Alfaguara - Penguin Random House Grupo Editorial S.A., Lima.

von Mises, L. (2018): La acción humana - Tratado de Economía (Estudio Preliminar de Jesús Huerta Soto), duodécima edición, España - Madrid: Unión Editorial, S.A.

Recibido: 29/03/2020

Aprobado: 12/06/2020

Hugo Ramiro Gómez Apac: Abogado por la Universidad Nacional Mayor de San Marcos. Magíster en Derecho de la Empresa por la Universidad Peruana de Ciencias Aplicadas.

Correo electrónico: hugo_gomez_apac@yahoo.com

Ciudad: Lima

País: Perú 
